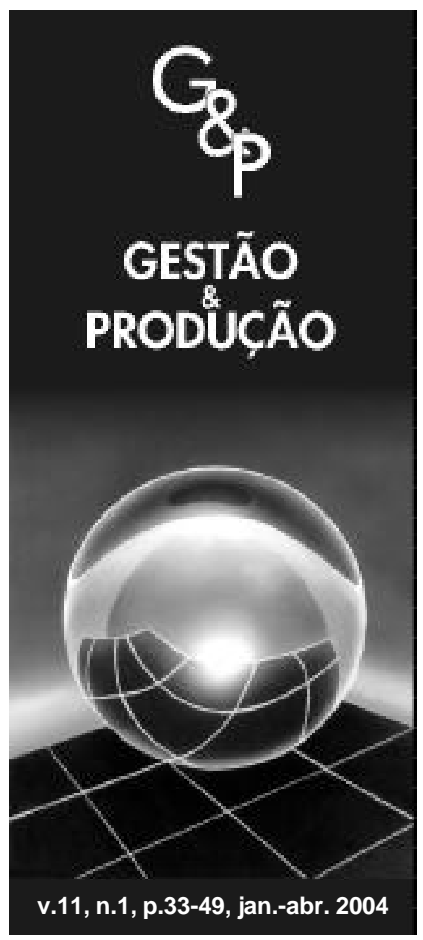

\title{
APLICAÇÃO DO QFD NO DESENVOLVIMENTO DE PRODUTOS: LEVANTAMENTO SOBRE SEU USO E PERSPECTIVAS PARA PESQUISAS FUTURAS
}

\author{
José Antonio Carnevalli \\ Andreza Celi Sassi \\ Paulo A. Cauchick Miguel
}

Núcleo de Gestão da Qualidade \& Metrologia, Faculdade de Engenharia Mecânica e de Produção, UNIMEP, Rod. SP 306, km 1, CEP 13450-000, Santa Bárbara d'Oeste, SP, e-mail: pamiguel@unimep.br

Resumo

O objetivo deste trabalho é avaliar a extensão do uso do QFD no Brasil, investigando, principalmente, as maiores empresas privadas por faturamento, de forma a identificar os benefícios e dificuldades para implementar o método, bem como organizações que já têm experiência com sua aplicação. Para atingir esse objetivo, um levantamento exploratório tipo survey foi realizado em uma amostra não aleatória, utilizando como instrumento para coleta dos dados um questionário enviado via correio. A taxa de retorno foi de aproximadamente $21 \%$, e os resultados indicaram que pouco mais de $18 \%$ das empresas utilizam o método. Essas empresas iniciaram a aplicação do QFD durante os anos 90, indicando que a utilização do QFD é relativamente recente no País. Em relação às dificuldades para implementar o QFD, o maior problema foi relacionado à falta de experiência em sua utilização. Quanto aos benefícios decorrentes do QFD, os mais importantes foram o aumento da satisfação dos clientes e a melhoria do trabalho em equipe $e$ comunicação entre áreas funcionais. Adicionalmente, a survey identificou cinco empresas com experiência em QFD, que podem ser consideradas referências no uso do método no País. Finalmente, o trabalho apresenta algumas perspectivas para pesquisas futuras.

Palavras-chave: desenvolvimento de produto, desdobramento da função qualidade, planejamento da qualidade, QFD.

\section{Introdução}

Durante a década de 1960, a indústria japonesa teve um período de grande crescimento. Em razão deste, a indústria automobilística daquele país realizava constantes alterações de modelo e lançamento de novos veículos. Isso criou a necessidade de um método que garantisse a qualidade do produto desde a fase de projeto (Akao, 1996). Entretanto, as empresas tinham grandes dificuldades para atingir esse objetivo.

Buscando uma solução para esse problema, Yoji Akao começou a realizar estudos que, com a união de sua pesquisa com as de Shigeru Mizuno, deram origem ao método conhecido como Quality Function Deployment (QFD) (Akao, 1996), traduzido para o português por Desdo- bramento da Função Qualidade. O QFD é um método de desenvolvimento de produtos, também utilizado para desenvolver serviços, que pretende garantir a qualidade desde as fases iniciais do projeto. Além disso, o QFD ouve as exigências dos clientes e as traduz em características mensuráveis, criando produtos e serviços que atendam e/ ou superem as expectativas desses clientes (Ohfuji et al., 1997).

Com o aumento da competição em escala mundial e em razão de seus benefícios, o QFD começou a ser usado em outros países, como EUA e Europa, durante a década de 1980, chegando ao Brasil na década de 1990. Apesar de o QFD já ser divulgado há cerca de dez anos no País, sua utilização ainda é relativamente recente, havendo, inclusive, escassez de dados sobre como é sua aplicação de forma mais 
abrangente. Procurando reduzir essa escassez de dados, esta pesquisa pretende ampliar o estudo realizado por Miguel \& Carpinetti (1999), utilizando uma amostra maior de empresas que empregam o método.

O objetivo da pesquisa é avaliar o grau de introdução do QFD no Brasil, estudando principalmente as maiores empresas privadas, por faturamento, identificando quais são os benefícios e dificuldades de implantação nas que já tenham experiência com o método. Neste trabalho serão apresentados o modo como foi definida a metodologia da pesquisa e a análise dos principais resultados deste estudo, buscando ainda relacionar parte desses resultados. No final, o trabalho apresenta algumas perspectivas para pesquisas futuras, visando a um aprofundamento no estudo sobre o método.

\section{Referencial teórico sobre QFD}

Neste tópico são apresentados os benefícios e dificuldades da implantação do método, assim como uma análise da evolução de sua implementação nos últimos sete anos. Também são descritos os resultados de duas pesquisas semelhantes a esta, realizadas no Brasil.

\subsection{Benefícios e dificuldades da implementação do QFD}

Entre as principais vantagens da utilização do QFD, encontradas na literatura, pode-se citar (Shina, 1991; Cheng et al., 1995; Ohfuji et al., 1997; Costa, 1999; Nogueira et al., 1999): melhoria do relacionamento entre os departamentos; diminuição no número de modificações de projetos e do tempo de desenvolvimento; e redução do número de reclamações e de custos. Pode-se citar também a identificação dos gargalos de engenharia, aumento da satisfação dos clientes, construção de base de dados com a documentação gerada pelo QFD e fortalecimento da prática da engenharia simultânea.

A literatura também relata as principais dificuldades no uso do QFD, a saber (Ekdahl \& Gustafsson, 1997; Cristiano et al., 2000; Martins \& Aspinwall, 2001): falta de suporte gerencial e de comprometimento dos membros da equipe do QFD; falta de recursos financeiros e de tempo para conduzir a consulta aos clientes; falta de experiência com o uso do método; longo tempo consumido com a aplicação; e dificuldades em trabalhar com matrizes muito grandes.

\subsection{Pesquisas tipo survey realizadas no Brasil sobre o uso do QFD}

Neste item serão apresentados os resultados de duas pesquisas semelhantes a este trabalho realizadas no Brasil em 1996 e 1999. O objetivo dessa apresentação é proporcionar uma visão geral de como o método estava sendo usado no País nos respectivos períodos, uma vez que este trabalho pretende apresentar um levantamento mais aprofundado sobre o uso do método no Brasil.

\subsubsection{Pesquisa realizada em 1996}

Em 1996, Damante (1997) realizou um estudo com os seguintes objetivos: verificar empresas que utilizam o QFD, qual seu impacto para atender o cliente e se o método gerava alguma vantagem competitiva.

Para atingir esses objetivos, foi realizada uma pesquisa de campo, exploratória, com amostragem não probabilística, por conveniência, formada por 1.024 empresas. Como técnica de coleta de dados foi usado um questionário. Para aprofundar os dados, foram realizadas cinco entrevistas com especialistas de empresas de consultoria e de universidades.

O índice de retorno da pesquisa de campo foi de $31,64 \%$. Deste total, apenas $15,43 \%$ utilizavam o método, tendo, em média, 2,6 anos de aplicação. Em relação aos benefícios do uso do QFD, os que mais se destacaram foram: redução de custo, melhoria dos preços e do ambiente de trabalho e redução no número de alterações após o lançamento do produto. Em relação às dificuldades na implementação do método, as principais foram: falta de técnicas para pesquisar o mercado, dificuldades de trabalhar em equipe, resistência dos departamentos a mudanças, e dificuldade na empresa por não ter uma cultura voltada para a qualidade.

O estudo concluiu que o método do QFD era pouco utilizado no Brasil, tendo baixo impacto no atendimento das necessidades e expectativas dos clientes, quando comparado a outras ferramentas de gestão. Entretanto, em alguns setores que o utilizavam, o método mostrava-se cada vez mais importante para atender às exigências dos clientes. Segundo Damante (1997), o QFD só é eficiente quando utilizado em uma empresa que tenha um sistema gerencial integrado trabalhando com qualidade total. Entretanto, pode haver exceções, como demonstrado por Paiva \& Cheng (2001), sobre a aplicação do método em uma empresa sem esse requisito.

\subsubsection{Pesquisa realizada em 1999}

Em 1999, foi realizada no País uma pesquisa de campo, exploratória, com amostragem não aleatória e intencional, em 111 empresas, utilizando a técnica de coleta de dados por questionário (Miguel \& Carpinetti, 1999). Os objetivos eram identificar e avaliar as empresas que utilizavam ou tinham planos de utilizar o QFD, os motivos que as levaram a usar esse método, quais as dificuldades encontradas na implementação e quais os benefícios conseguidos com seu uso.

O índice de retorno dos questionários foi de 27,9\%, sendo que, deste total, 32,3\% utilizavam o QFD. Nessa pesquisa, verificou-se que o uso do método ainda era relativamente recente no País, sendo que a maior parte das empresas estudadas só começou a implementá-lo a partir de 1997. Desse modo, as empresas que constavam na amostra ainda não tinham experiências consolidadas. 
A partir dos resultados, pôde-se constatar que a empresas iniciaram o uso do QFD buscando, principalmente, a melhoria no processo de desenvolvimento de produto e o aumento da satisfação dos clientes. Os principais benefícios apontados foram: melhoria da qualidade e da confiabilidade e melhoria das equipes de trabalho e da prática de engenharia simultânea. As principais dificuldades foram: atribuir peso e interpretar os requisitos dos clientes, conflitos de opiniões nos grupos e falta de treinamento. Sobre os efeitos do QFD, verificouse que a grande maioria das empresas acredita que ele é "neutro", ou seja, o QFD não gera nenhum resultado positivo ou negativo, e apenas $30 \%$ consideram seus efeitos nos projetos como "bom" e "um sucesso". Os autores acreditam que isso se deve à falta de experiência com o uso do método (Miguel \& Carpinetti, 1999).

\subsection{Análise da evolução das publicações sobre o QFD no Brasil}

Com o objetivo de verificar a evolução da implantação do QFD nos últimos sete anos, foram estudados artigos publicados em alguns eventos, como: ENEGEP (Encontro Nacional de Engenharia de Produção) de 1995 a 2001; 1ำ, $2^{\circ}$ e 3 - Congressos Brasileiros de Gestão de Desenvolvimento de Produto (1999, 2000, 2001, respectivamente); SIMEA (Simpósio Internacional de Engenharia Automotiva), realizado em 1997, 1999 e 2001; e I CONEM 2000 (Congresso Nacional de Engenharia Mecânica). Como resultado, a Figura 1 mostra a evolução do uso do QFD a partir das experiências publicadas nos últimos anos, indicando o número de artigos surgidos nos anais desses eventos. No total foram analisados 14 anais, tendo sido encontradas 61 publicações sobre o QFD.

Pode-se observar que, nos três últimos anos, vem aumentando o número de publicações de artigos nos eventos verificados (37,7\% do total no ano de 2001). Apesar de terem sido estudados três anais em 2000 (CONEM, ENEGEP, 2ㅇ Congresso Brasileiro de Gestão de Desenvolvimento de Produto), houve redução do número de artigos publicados nesse ano em relação aos anos de 1999 e 2001, quando foram pesquisados outros eventos (ENEGEP, SIMEA e Congresso Brasileiro de Gestão de Desenvolvimento de Produto). No CONEM 2000, houve apenas duas publicações de artigos sobre o QFD, justificando, assim, a queda de publicações. Além disso, como o congresso tem o caráter mais direcionado para a Engenharia Mecânica, seria mesmo esperada uma menor quantidade de publicações em áreas mais voltadas para a Engenharia de Produção. É importante também ressaltar que o SIMEA ocorre a cada dois anos, em anos ímpares.

A partir desse estudo, verificou-se que o QFD vem sendo mais aplicado no setor de serviços (mais da metade), na tentativa de melhorar a prestação de serviços com o método. Dos artigos estudados, 38,9\% usaram o QFD para desenvolver produtos e $61,1 \%$ para desenvolver serviços (foram desconsiderados os artigos sobre estudo da metodologia do QFD). No setor de serviços, observou-se que o QFD foi aplicado em $8,1 \%$ dos casos em saúde, $5,4 \%$ dos casos em ensino e 2,7\% em todos os casos relativos às telecomunicações, Internet, clubes, laboratórios, shoppings centers, serviços automotivos, entre outros. No desenvolvimento de produtos, as aplicações mais freqüentes foram para produtos automotivos $(20,8 \%)$ e alimentos (12,5\% dos casos). Após a análise, verificou-se que todas as empresas que implantaram o método do QFD alcançaram resultados positivos.

\section{Metodologia da pesquisa}

Para atingir os objetivos deste estudo, foi realizada uma pesquisa de campo exploratória, com amostra não aleatória e intencional. Como essa amostra não foi probabilística, não é possível afirmar que é representativa de todas as empresas que operam no País. Entretanto, cabe destacar que a amostra inclui as 500 maiores empresas por faturamento. Assim, podese considerar certa representatividade da amostra, visto que esta representa parcela significativa, em termos financeiros, em relação ao PIB (aproximadamente metade do PIB). Essa amostra foi formada por empresas privadas que estavam na classificação da revista Exame (2000) e por empresas que a equipe deste trabalho já tinha conhecimento que usavam o QFD, estavam implementando ou tinham planos de implementar. Para a coleta de dados, usou-se um questionário, em razão da pouca disponibilidade de recursos para realizar uma pesquisa por meio de entrevistas com amostra grande (506 empresas), distribuída por todo o território nacional.

Na elaboração do questionário, priorizou-se o uso de perguntas fechadas, pelo fato de serem fáceis de tabular e por coletar boa quantidade de informações, mas também foram usadas algumas questões abertas. As perguntas do questionário foram agrupadas e ordenadas em oito blocos, relacionados ao perfil da empresa, implantação do QFD, resultados obtidos pelo método, entre outros. Visando a aprimorar o instrumento de coleta de dados, a equipe de trabalho realizou dois pré-testes: um com dois professores da área e outro com três empresas (uma que usa o método, outra que está implementando e uma terceira que não utiliza). Com os resultados, verificou-se a necessidade de aumentar os espaços de preenchimento das questões abertas, de criar duas novas questões e eliminar uma já existente.

Em razão das dificuldades em conseguir os endereços das empresas da amostra, houve atraso no cronograma. A equipe também enfrentou alguns problemas na devolução dos questionários pelo correio, como, por exemplo, extravios nas próprias empresas. Para melhorar o índice de retorno na pesquisa, foi enviada uma carta junto com o questionário, explicando os objetivos da pesquisa, e um envelope endereçado para a devolução. Posteriormente, foram enviadas duas outras cartas lembrando sobre a importância de participação das empresas.

Com o retorno dos questionários, estes passaram por um processo de verificação, codificação e tabulação. Neste trabalho, foi realizada tabulação parcialmente manual e 
eletrônica no Excel, e com eles foram realizados gráficos para análise dos resultados.

No próximo item, serão apresentados os resultados da pesquisa e sua análise.

\section{Apresentação e análise dos resultados}

Esta pesquisa teve uma taxa de retorno de quase $21 \%$ na devolução dos questionários (106 questionários, desconsiderando os 21 recebidos em branco), o que está dentro do índice de devolução citado por Mattar (1996), que é de $3 \%$ a $50 \%$. Com a análise desses questionários, verificou-se que mais de $81 \%$ das empresas não utilizam o método (86 empresas), pouco mais de $9 \%$ utilizam regularmente (10 empresas) e pouco mais de $9 \%$ estão implementando (10 empresas). A pesquisa de Damante (1997) apresentou uma taxa de retorno maior, mas isso se deve à diferença nas amostras. Neste trabalho, a maioria dos questionários não foi endereçada especificamente a algum profissional da empresa, o que não ocorreu com a pesquisa conduzida por Damante (1997), em que, na grande maioria dos casos, foi endereçada ao responsável pelo setor da qualidade.

\subsection{Informações sobre as empresas pesquisadas}

Sobre o setor de atuação industrial das empresas que devolveram o questionário, destacaram-se os seguintes: Produtos alimentícios, bebidas, fumo, com quase $15 \%$ dos casos; Produtos químicos, com mais de $9 \%$ dos casos; Serviços: eletricidade, gás e água; e Automobilístico, cada um com mais de $8 \%$ dos casos. Para a classificação das empresas, por setor econômico-industrial, foi feita uma adaptação da classificação nacional de atividades econômicas (Oliveira, 1999). Ao analisar o porcentual dos setores na amostra e o porcentual de devolução, constatou-se que estes são muito próximos (diferença de poucos pontos percentuais), de certa forma auxiliando a validar a devolução. Sobre o setor de atuação das empresas que utilizam o QFD, destacaramse os setores Automobilísticos, Eletrodomésticos e Metalúrgica básica, cada um com $15 \%$ dos casos, e os setores Produtos alimentícios, bebida, fumo, Máquinas e equipamentos e Produtos químicos, cada um com $10 \%$ dos casos.

A Figura 2 apresenta os tipos de clientes a que as empresas atendem; a coluna preta indica os resultados das empresas que responderam à questão (100\% equivale a 86$)$; a coluna cinza apresenta os resultados das empresas que utilizam o QFD e responderam a questão, sendo que, das 20 empresas que usam o método, uma não respondeu a esse questionamento (nesse caso, $100 \%$ equivale a 19); e a coluna branca apresenta os resultados das empresas que não usam o QFD e responderam à questão (nesse caso, $100 \%$ equivale a 67).

Comparando-se separadamente as empresas que usam e as que não usam o QFD, verificou-se que as que usam o método atendem, em metade dos casos, a ambos os clientes (pessoa física ou jurídica) e as que não usam atendem em mais de $60 \%$ (mais de $18 \%$ usuário final e mais de $42 \%$ cliente intermediário) a um dos dois tipos de clientes. Apesar de os resultados serem próximos, verifica-se uma tendência de empresas que têm mais de um tipo de cliente usarem mais o método. Neste estudo, não foi possível comprovar essa hipótese, mas seria interessante investigar mais detalhadamente essa tendência, que poderia estar relacionada à dificuldade em satisfazer mais de um tipo de cliente, levando as empresas a buscarem outros métodos de desenvolvimento de produto, como o QFD.

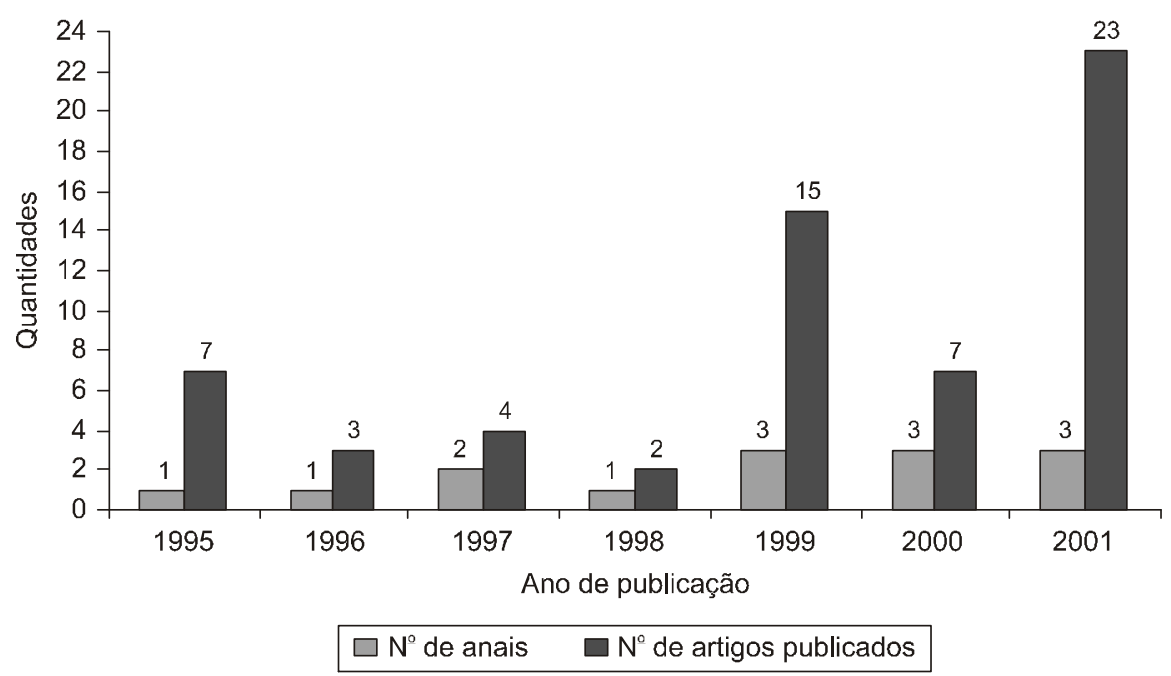

Figura 1 - Evolução do QFD Brasil de 1995 a 2001 (Sassi \& Miguel, 2002). 


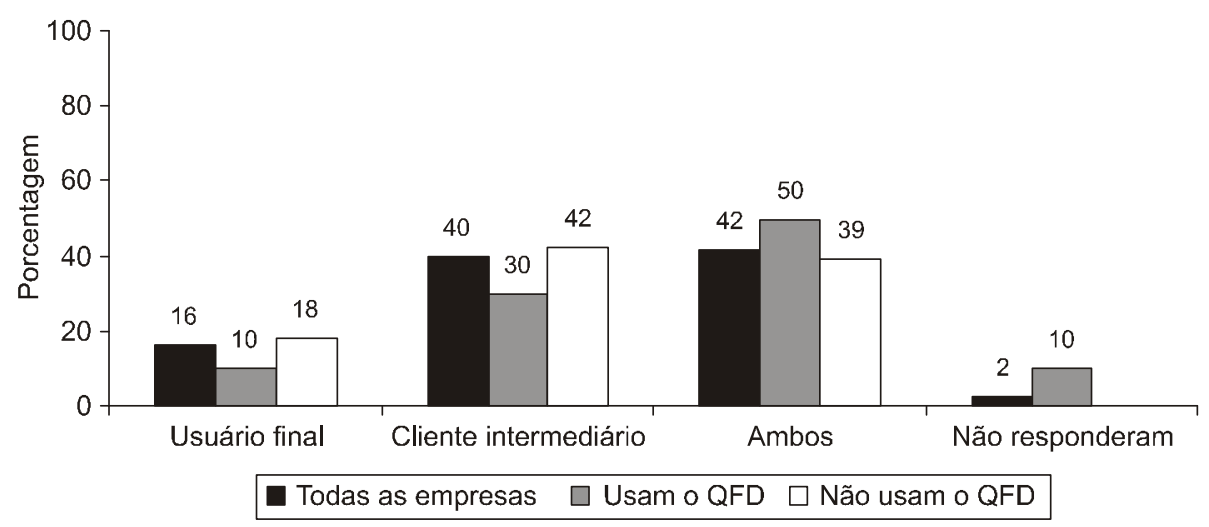

Figura 2 - Tipo de cliente a que a empresa atende.

Analisando-se o porcentual de empresas que participaram da pesquisa e que estão entre as 10,50 e 100 primeiras por lucro, segundo a classificação da revista Isto é Dinheiro (2000), verifica-se que apenas pouco mais de $13 \%$ das empresas estão entre as 100 primeiras por vendas. Considerando apenas as empresas que usam o QFD, esse número sobe para $25 \%$. Uma hipótese para esses resultados é que o QFD pode estar afetando positivamente os lucros das empresas, caso ele gere benefícios, como redução de custo e aumento das vendas. Isso é compatível com o fato verificado neste estudo de que 55\% das empresas consideram como "satisfatório", "bom" ou "excelente" a redução de custos gerada com o uso do método.

Verifica-se na pesquisa que, das empresas que não utilizam o QFD, mais de 55\% não têm planos de implementar o método, pouco mais de $23 \%$ têm planos de implementar o QFD a médio prazo (de um a dois anos) e apenas pouco mais de $13 \%$ têm planos de usar o QFD a curto prazo (até um ano). Quando perguntado para essas empresas por que não utilizam o QFD, seus principais motivos foram: o método não é de interesse da empresa no momento e as empresas têm uma maneira própria de atender às necessidades dos clientes. Como terceiro aspecto mais apontado, com mais de $26 \%$ dos casos, as empresas sequer conheciam o QFD, mostrando a necessidade de maior divulgação do método.

\subsection{Dados sobre a aplicação do QFD}

Em função da extensão do questionário, uma quantidade significativa de dados e informações foi obtida no levantamento. Assim, visando a uma melhor organização desses resultados, este item é subdividido de acordo com os tipos de resultados. Os resultados mais detalhados sobre o levantamento podem ser encontrados em Miguel (2003).

\subsubsection{Porte e localização geográfica das empresas}

Em relação ao porte das empresas, foram considerados os critérios do Prêmio Nacional da Qualidade (PNQ), rela- cionado ao número de funcionários: empresas com até 50 pessoas são consideradas pequenas empresas, de 51 a 500, médias e com mais de 500 colaboradores, grandes empresas. Das 20 que utilizam o QFD, 15\% são de médio porte e o restante, de grande porte. Este resultado era esperado, em decorrência do tipo da amostra da pesquisa, formada principalmente pelas 500 maiores empresas por vendas no País.

As empresas que usam o QFD estão localizadas, principalmente, no Estado de São Paulo (55\% dos casos). Esses resultados são compatíveis com a amostra da pesquisa, em que em mais de metade dos casos as empresas estavam localizadas nesse Estado.

\subsubsection{Início na implantação do QFD, motivos para uso e finalidade na aplicação}

Verifica-se na pesquisa que a maioria das empresas iniciou a implantação do QFD após a metade da década de 1990 (60\% dos casos), tendo, no máximo, seis anos de experiência. Assim, seu uso ainda pode ser considerado relativamente recente.

Os principais motivos que levaram as empresas a iniciarem a implantação do QFD foram: "melhoria do processo de desenvolvimento de produto", "decisão a partir do conhecimento de suas vantagens" (pela literatura) e "aumento da satisfação dos clientes".

Verifica-se que as empresas usam o QFD principalmente para desenvolver produtos $(70 \%)$, em $15 \%$ dos casos utilizam o método para desenvolver processos e produtos e em $10 \%$ das empresas utilizam o QFD para desenvolver processos. Não foi identificada nesta pesquisa seu uso no desenvolvimento de serviços e software, diferentemente do que ocorreu na pesquisa similar realizada nos EUA e no Japão (Cristiano et al., 2000).

\subsubsection{Modelo teórico e matrizes adotadas}

Quanto ao modelo do QFD que as empresas adotaram, em $25 \%$ dos casos elas não sabem defini-lo, mostrando possível deficiência no treinamento em relação à fundamentação teórica do método. Em 30\% dos casos 
utilizam o modelo das Quatro Ênfases (modelo japonês), em $15 \%$, o modelo das Quatro Fases, sendo este o mais utilizado nos EUA (Cristiano et al., 2000), e em 10\%, o modelo do QFD-Estendido.

Quando perguntado se as empresas só realizam a matriz da qualidade, $25 \%$ responderam que sim, $70 \%$ responderam que outras matrizes também são realizadas e $5 \%$ não responderam à questão. Isso é significativo, pois não é possível garantir que a empresa conseguirá atingir os valores de qualidade realizando apenas a primeira matriz (Cheng et al., 1995).

\subsubsection{Aspectos relativos às equipes e reuniões de QFD}

O número médio de participantes na equipe do QFD é de 6 membros, mas, realizando-se uma análise mais detalhada, verifica-se que as equipes de trabalho do QFD têm de 4 a 7 pessoas em $45 \%$ dos casos, o que está dentro do recomendado por Ohfuji et al. (1997). Entretanto, em $40 \%$ dos casos, o número ficou acima de 7 participantes e, em 5\%, abaixo de 4, estando fora do recomendado na literatura. Isso pode causar alguns problemas na condução do trabalho, pois, segundo Ohfuji et al. (1997), equipes com mais de 7 pessoas são muito grandes e podem gerar maior discussão e com menos de 4 são muito pequenas, podendo causar atraso nos trabalhos decorrente da distribuição das tarefas. Entretanto, para poder afirmar categoricamente, esse aspecto deve ser melhor pesquisado.

Quando perguntado às empresas qual a frequiência das reuniões das equipes de trabalho do QFD, $40 \%$ responderam que as reuniões são semanais e 30\%, quinzenais. Esses valores são muito próximos dos resultados conseguidos na pesquisa similar realizada na Suécia (Ekdahl \& Gustafsson, 1997), onde em quase $47 \%$ dos casos as reuniões são semanais e em $30 \%$ dos casos, quinzenais.

A duração média das reuniões das equipes do QFD é de uma a duas horas, em $50 \%$ dos casos, e de meio dia em $25 \%$ dos casos. Na pesquisa similar da Suécia (Ekdahl \& Gustafsson, 1997), verifica-se que a duração das reuniões é mais longa, estendendo-se por meio dia, o que pode acelerar o processo de aplicação. É importante lembrar que, sendo o método executado sempre por uma equipe, a frequiência e a duração das reuniões devem influenciar diretamente o tempo de projeto.

As equipes de QFD envolvem principalmente pessoas das áreas de Produção, Engenharia de Processo e Engenharia de Produto, cada uma dessas áreas apontadas por $80 \%$ das empresas, além da área da Qualidade, apontada por $75 \%$ das empresas (nessa questão mais de uma área funcional poderia ser selecionada). A opção "outros" foi selecionada por $65 \%$ das empresas, envolvendo as seguintes áreas: Marketing, Laboratório, Ferramentaria, Engenharia de Manutenção e Serviço de Atendimento ao Cliente (SAC). Segundo Miguel (2001), a importância de empregar uma equipe multifuncional está na contribuição do conhecimento técnico e na experiência de cada participante, além de as decisões tomadas não ficarem centradas numa única pessoa, mas, sim, serem um consenso da equipe.

\subsubsection{Treinamento no método}

Sobre a duração do treinamento em QFD, em 30\% dos casos é de três dias e em $20 \%$, de meio dia. Períodos de treinamento de um a dois dias ou de mais de três dias foram apontados por cerca de $10 \%$ das empresas. Para Cheng et al. (1995), o treinamento deve ser de uma semana para os membros da equipe de QFD, e de seis horas para as pessoaschave, as quais são originárias das áreas envolvidas com o projeto. Isso é necessário para que essas pessoas tenham um conhecimento básico sobre o assunto. Desse modo, se a sugestão dos autores (Cheng et al., 1995) estiver correta, as empresas estão realizando um treinamento com carga horária menor que a recomendada, o que pode estar contribuindo para as dificuldades na implantação por falta de experiência em QFD. Este assunto precisaria ser melhor investigado, a fim de aprimorar essa análise.

\subsubsection{Obtenção dos requisitos dos clientes}

Sobre como as empresas obtêm os requisitos dos clientes, tendo por base uma lista de opções para escolha, as empresas assinalaram as seguintes práticas: técnica de entrevista (frequiência de 65\%), informações fornecidas por vendas (55\% dos casos) e relatórios de reclamações (50\%). Esses dados são positivos, já que as empresas estão usando informações adquiridas externa e internamente, podendo identificar, assim, as expectativas dos clientes e os problemas de seus produtos atuais por meio dos canais de comunicação com os clientes.

\subsubsection{Dificuldades encontradas}

As principais dificuldades encontradas durante a implantação do QFD podem ser vistas na Figura 3, em que se destacam: "falta de experiência em QFD", "falta de comprometimento dos membros do grupo" e "trabalhar com matrizes muito grandes". Essas dificuldades também foram encontradas em trabalhos similares (Ekdahl \& Gustafsson, 1997; Martins \& Aspinwall, 2001).

A maioria das empresas (55\% dos casos) não contratou uma consultoria para a implementação do QFD. Entretanto, as empresas indicaram como uma das principais dificuldades para implementar o método a falta de experiência em QFD (mostrado na Figura 3), de certa forma contradizendo os resultados em relação às dificuldades, já que o uso de uma consultoria poderia reduzir as dificuldades por falta de experiência no método.

Para evitar problemas como a falta de comprometimento do grupo, segundo Cheng et al. (1995), deve-se escolher um 
líder de equipe que tenha autoridade sobre o desempenho de seus membros, controlando, assim, seu trabalho.

Em relação ao tamanho das matrizes, a GM dos EUA criou o "Processo de QFD Simplificado" (The Streamlined QFD Process). Segundo Ross (1999), por esse processo, a empresa faz uma análise crítica para identificar os requisitos e características da qualidade mais importantes, e somente estes farão parte da matriz. Desse modo, é possível reduzir o tamanho da matriz e, consequientemente, o tempo de aplicação do método, contribuindo para a redução no tempo de desenvolvimento.

\subsubsection{Benefícios da aplicação do método}

Os principais benefícios do uso do QFD são mostrados na Figura 4. Os benefícios que mais se destacaram foram: "aumento da satisfação do cliente", "melhoria da co- municação interfuncional", "melhoria do trabalho em grupo" e "aumento da qualidade e confiabilidade". Com esses resultados, verifica-se que as empresas estão conseguindo os benefícios que elas buscavam quando iniciaram a implantação do método, anteriormente apresentados.

\subsubsection{Avaliação sobre a utilização do método e número de projetos concluídos}

Quando perguntado para as empresas como elas avaliaram a implantação do QFD, $45 \%$ responderam que não fazem avaliação, somente $25 \%$ fazem avaliação no final da aplicação do método e $15 \%$ fazem avaliação periódica. Esses dados são preocupantes, pois sem avaliar a implantação não é possível identificar se os investimentos justificaram os resultados gerados pelo método.

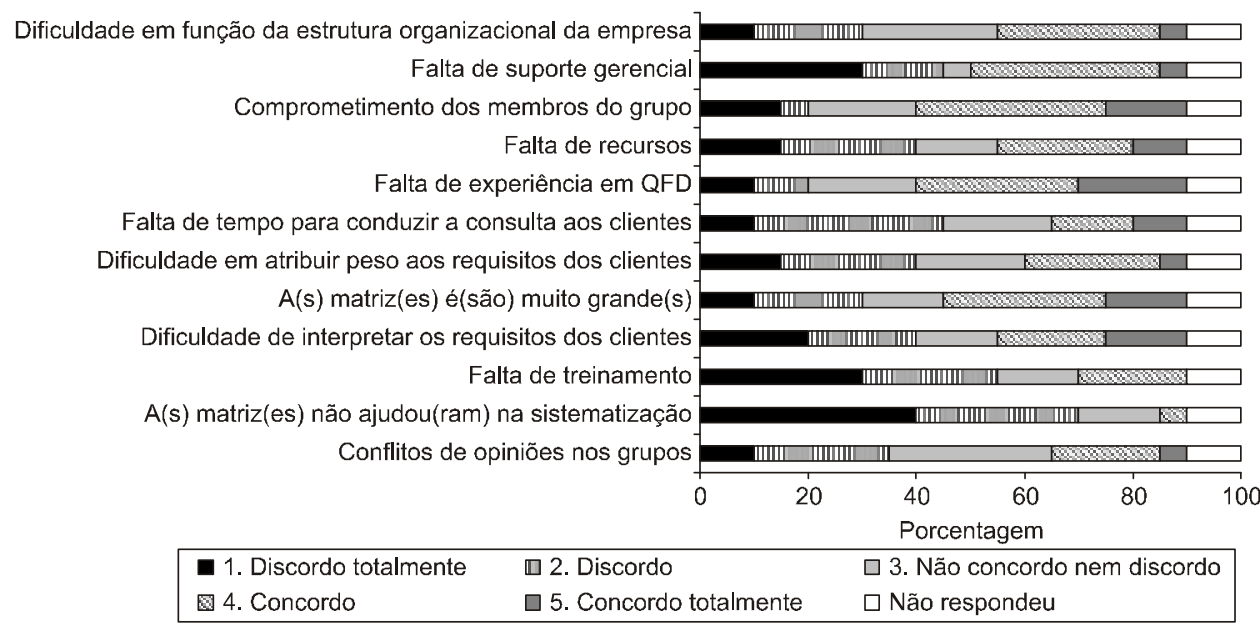

Figura 3 - Principais dificuldades para implementar o QFD.

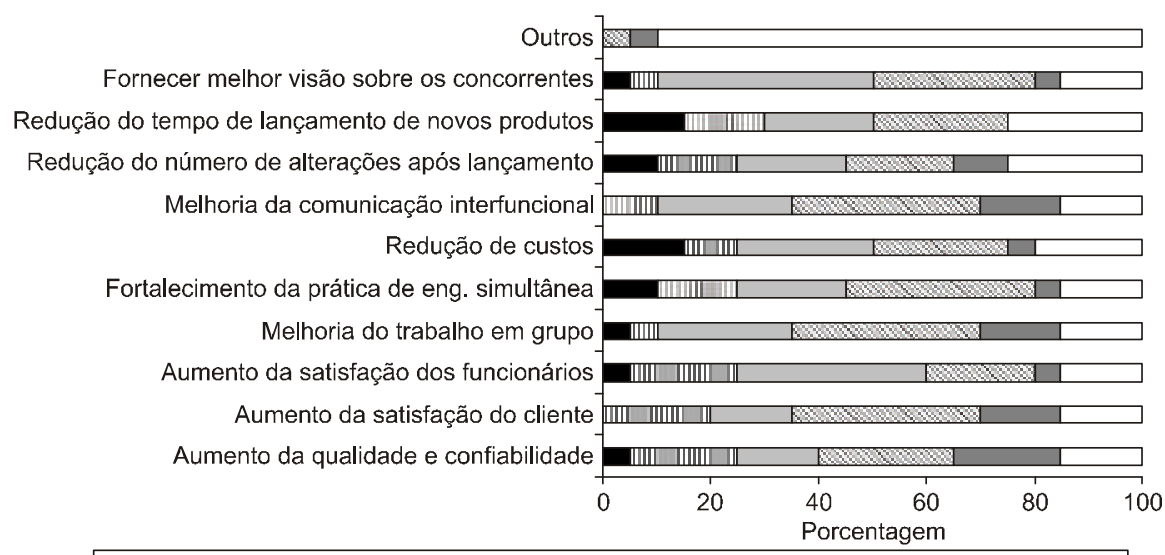

. Não houve $\square$ 2. Pouco $\square$ 3. Satisfatório $\square$ 4. Bom $\square 5$. Excelente $\square$ Não responderam

Figura 4 - Benefícios da implantação do QFD. 
Verificou-se também que mais da metade das empresas não faz registro das melhorias alcançadas com o uso do QFD. Apenas em 30\% dos casos, as empresas responderam que estão registrando essas melhorias. Desse modo, a maioria das empresas não pode demonstrar os resultados positivos ou negativos com o uso desse método.

A pesquisa também verificou que apenas pouco mais de $15 \%$ das empresas avaliam os custos de implantação do QFD. Novamente, como destacado anteriormente, isso é preocupante, pois assim não podem comprovar a relação custobenefício com o uso do método.

Em relação ao uso do QFD nos projetos, a maioria (55\%) avalia como "bom", 15\%, como "indiferente" e somente $10 \%$, como "ruim". Em relação aos resultados gerais do QFD, a maioria considera como "bons" ou "ótimos" (em $60 \%$ dos casos) e em $20 \%$ dos casos, como "indiferentes" ou "ruins".

Quanto ao número de projetos concluídos com o uso do QFD, em 15\% dos casos as empresas não têm nenhum projeto concluído, mas em $10 \%$ têm 1 projeto, em $25 \%$ dos casos, 2 ou 3 projetos e em $30 \%$ dos casos, as empresas têm mais de 3 projetos concluídos. Deste modo, mais da metade das empresas têm mais de um projeto concluído.

\subsubsection{Sucesso no uso do QFD e pontos importantes para alcançá-lo}

Sobre se a implementação do QFD obteve sucesso, $35 \%$ responderam que teve "sucesso parcial", 30\% teve "sucesso" e 15\% não teve. Em razão da limitação do questionário, não foi possível identificar o que as empresas consideram como "sucesso parcial", sendo que algumas respostas são contraditórias, quando comparadas à avaliação do uso do método pelas empresas. Essa foi uma das limitações encontradas no instrumento de coleta de dados. Essa discussão sobre o sucesso com o uso do método é também realizada no item 5 .

Foi solicitado que as empresas distribuíssem 100 pontos nos itens que elas considerassem mais importantes para ter sucesso na implementação do QFD. Destacaramse: "ter apoio da alta gerência", "analisar e interpretar as informações e resultados adequadamente", "conduzir pesquisa de mercado eficaz" e "proporcionar treinamento adequado", mostrando a importância do apoio da alta gerência e de definir corretamente o mercado e sua amostra. Segundo Cheng et al. (1995), o apoio da alta gerência é um dos pré-requisitos necessários para que a implantação do QFD tenha sucesso. Isto porque o método gera mudanças estruturais e de procedimentos, que não seriam possíveis sem esse apoio. Os autores também destacam o treinamento como fator de sucesso para o uso do método, demonstrando que os resultados da pesquisa estão em concordância com a literatura.

\subsubsection{Empresas que interromperam o uso do QFD}

Também foi investigado, embora de forma limitada, alguns aspectos relativos sobre as empresas que interromperam o uso do método. Entre os motivos que levaram essas empresas (25\% dos casos) que utilizavam o QFD a interromper seu uso estão: "as expectativas não foram alcançadas", em $60 \%$ dos casos; "problemas durante a implantação", em 40\%; "decisão gerencial", em 20\%; "outros fatores", em 40\%, como dificuldade em razão da estrutura da Engenharia de Desenvolvimento.

\section{Cruzamento e análise dos dados}

Neste item é apresentado o cruzamento de alguns dos resultados do estudo, principalmente relativos às seguintes variáveis: porte das empresas, execução de treinamento, utilização de apoio externo por meio de consultoria, tamanho e tipo de matrizes adotadas, versões/modelos de QFD, resultados e avaliação sobre o uso do método, bem como benefícios decorrentes da implementação. Considera-se este item como a maior contribuição deste trabalho, juntamente com o anterior, ressaltando-se que um maior detalhamento sobre os resultados brutos (sem o cruzamento destes) foram apresentados em outra oportunidade (ver Miguel, 2003).

Analisando-se separadamente as empresas de tamanhos médio e grande em relação à duração do treinamento em QFD, verifica-se que as empresas médias realizam treinamento de até dois dias e as empresas grandes, treinamentos acima de dois dias, em mais de $47 \%$ dos casos. Essa tendência pode estar relacionada à menor disponibilidade de recursos nas empresas de médio porte, mas seria necessário aprofundar o estudo com novas pesquisas para verificar as causas.

Um dado interessante é que as empresas médias não apresentaram dificuldades por falta de suporte gerencial, diferente do que ocorre em mais de $47 \%$ dos casos das empresas grandes. Em razão do pequeno número de empresas de tamanho médio na amostra (3 empresas), este resultado não é conclusivo, mas mostra uma tendência que precisa ser melhor investigada.

Na Figura 5 verifica-se a influência do tamanho das empresas na implementação do QFD. Os resultados mostram uma tendência de as empresas grandes terem mais dificuldade em conseguir sucesso na implantação do QFD, mas esse resultado também não é conclusivo, em razão do tamanho da amostra de usuários do método.

Na Tabela 1 são analisadas as 6 empresas que contrataram consultoria e as 11 que não contrataram, em relação às dificuldades de implementação.

Verifica-se que empresas que contam com o apoio de uma consultoria têm menos dificuldades em trabalhar com 
matrizes grandes, o que também vale para a falta de experiência em QFD. Dificuldades docorrentes da "falta de recursos" teve índice de resposta de $0 \%$ para as empresas que contrataram consultoria e de quase $64 \%$ para as empresas que não contrataram. Uma possível razão para esse resultado, que precisa ser melhor investigado para ser comprovado, é que, com a presença de um consultor, a empresa toma conhecimento de quais recursos são necessários para o uso do método, providenciando-os. Um fato interessante é que os índices de dificuldades por falta de suporte gerencial e de comprometimento dos membros do grupo aumentam nos casos em que as empresas contrataram uma consultoria. Um provável motivo, que também deveria ser melhor investigado em futuros estudos, é que essas dificuldades devem ocorrer na mesma proporção tanto nas empresas que contrataram uma consultoria quanto nas que não contrataram, porém são melhor percebidas nas empresas que têm um consultor, em razão da experiência deste com o método.

Na Figura 6 analisa-se o efeito do uso ou não de uma consultoria nas 20 empresas que implementaram o QFD. Verifica-se que as empresas que não tiveram apoio de uma consultoria apresentaram maiores índices de "sucesso parcial" ou "sem sucesso" na implantação.

As Figuras 7 e 8 verificam se a realização somente da matriz da qualidade influencia os resultados e a avaliação do QFD nos projetos. Os resultados indicam que sim. $\mathrm{O}$ uso apenas da matriz da qualidade prejudica os resultados do método e sua avaliação no projeto, já que empresas que realizam mais de uma matriz tiveram melhores avaliações sobre o método.

A Figura 9 identifica os principais benefícios do QFD, conseguidos por empresas que só realizaram a matriz da qualidade (total de 4 empresas). Os benefícios que mais se destacaram foram "melhoria da comunicação interfuncional" e "melhoria do trabalho em grupo". Esses benefícios são consequiência do uso de equipes multifuncionais do que de melhorias geradas pelo resultado da matriz. Outros benefícios também foram apontados, a saber: "fornecer uma melhor visão sobre os concorrentes", que é inerente à elaboração da primeira matriz; "fortalecimento da prática de engenharia simultânea", que também é conseqüência do uso de equipes multifuncionais.

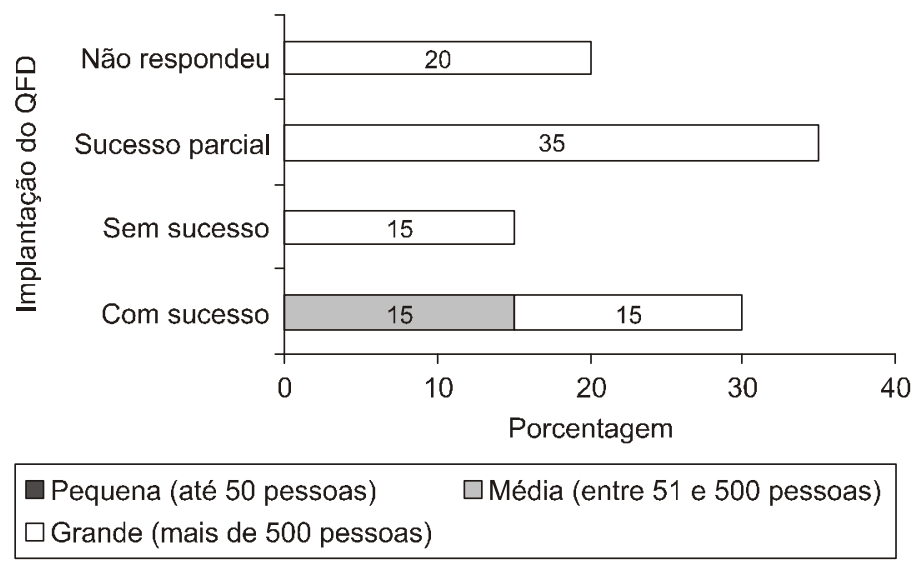

Figura 5 - Influência do tamanho da empresa na implantação do QFD.

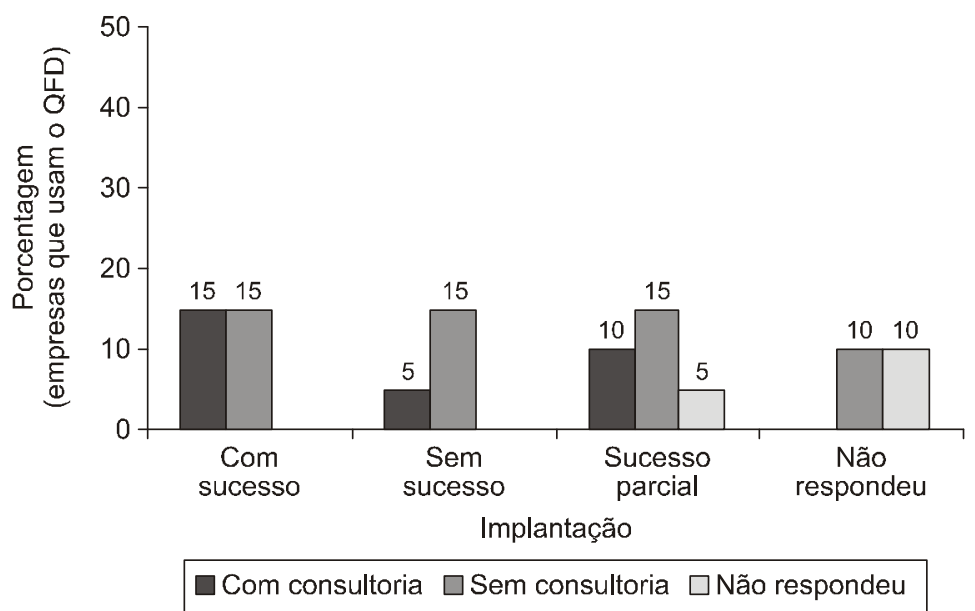

Figura 6 - Influência do uso de consultoria na implementação. 
Tabela 1 - Influência do uso de uma consultoria nas dificuldades de implementação.

\begin{tabular}{lcc}
\hline \multicolumn{1}{c}{ Dificuldades } & Com consultoria & Sem consultoria \\
\hline Falta de suporte gerencial & $83,3 \%$ & $18,2 \%$ \\
Comprometimento dos membros do grupo & $66,7 \%$ & $45,5 \%$ \\
Falta de experiência em QFD & $50 \%$ & $54,6 \%$ \\
Falta de recursos & $0,0 \%$ & $63,7 \%$ \\
A(s) matriz(es) é (são) muito grande(s) & $50 \%$ & $54,6 \%$ \\
\hline
\end{tabular}

Os resultados apresentam a somatória das respostas " 4 - concordo" e "5 - concordo totalmente" da questão 3.6: "Indicar na escala de 1 a 5 os principais problemas encontrados pelos usuários na implementação do QFD”.

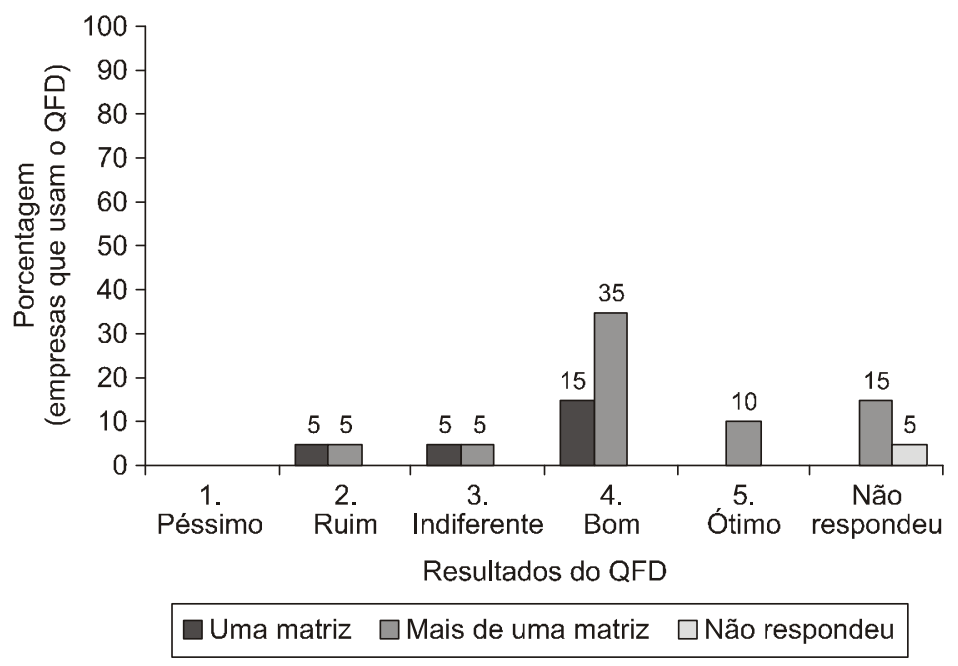

Figura 7 - Influência do número de matrizes realizadas nos resultados.

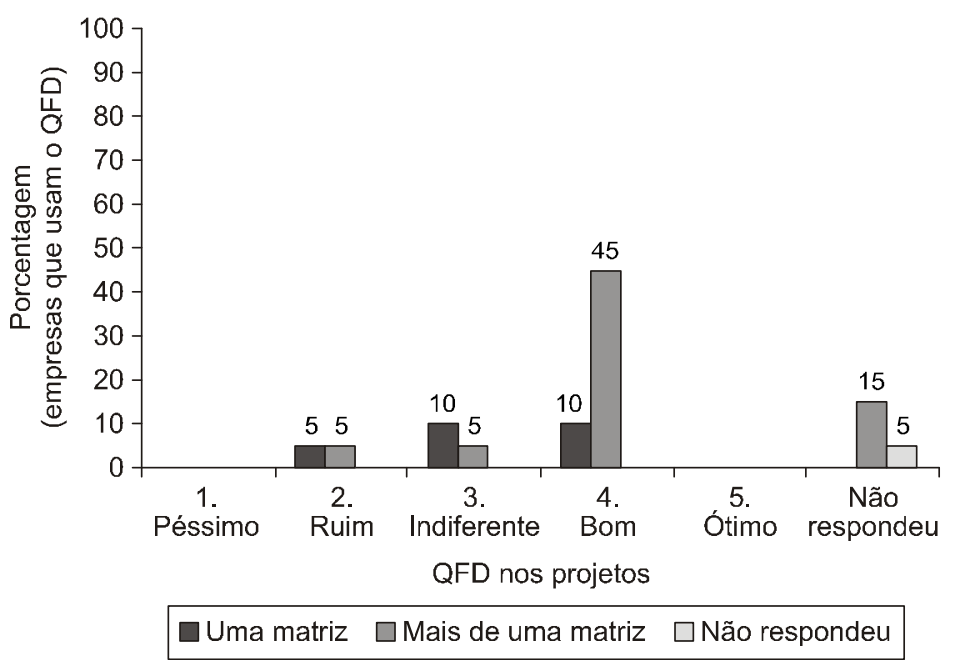

Figura 8 - Influência do número de matrizes realizadas na avaliação do projeto.

Na Figura 10 apresentam-se os benefícios conseguidos por empresas que utilizam mais de uma matriz do QFD (total de 14 empresas). Os benefícios que mais se destacaram foram: "aumento da qualidade e confiabilidade"; "aumento da satisfação do cliente"; "melhoria do trabalho em grupo"; e "melhoria da comunicação interfuncional".

Com a análise das Figuras 9 e 10, verifica-se que o uso apenas da matriz da qualidade gera menos benefícios, mostrando a importância de a empresa identificar e realizar 
também outras matrizes, necessárias para ela atingir a qualidade projetada, definida na matriz da qualidade. Além disso, a realização de mais de uma matriz também interfere positivamente no sucesso da implementação do QFD, como pode ser visto na Figura 11.

A Figura 12 apresenta uma contradição que deve ser melhor investigada. Mais de 57\% das empresas que tiveram "sucesso parcial" na implementação avaliam o uso do QFD nos projetos e seus resultados como "bom", e mais de $14 \%$ consideram os resultados do QFD como "ótimo".

A Tabela 2 apresenta as principais dificuldades de implementar o QFD, separadas pelas diferentes versões do método: QFD das Quatro Ênfases (seis empresas usando), QFD-Estendido (duas empresas usando) e QFD das Quatro Fases (três empresas usando). As principais dificuldades encontradas em cada uma das versões foram: QFD das Quatro Fases: "falta de recursos" (em 66\% dos casos). QFD-Esten- dido: destacam-se as dificuldades "comprometimento dos membros do grupo", "falta de suporte gerencial", "dificuldade em função da estrutura organizacional da empresa", "falta de recursos" e "falta de experiência em QFD", cada uma com $100 \%$ dos casos (duas empresas). QFD das Quatro Ênfases: destacam-se "falta de suporte gerencial" e "comprometimento dos membros do grupo", cada uma com $67 \%$ dos casos, além de "falta de experiência em QFD" em 50\% dos casos.

Comparando as dificuldades encontradas por essas 11 empresas, deve-se considerar que, como apenas 3 empresas estão usando o modelo do QFD das Quatro Fases e 2, o modelo do QFD-Estendido, não é possível fazer uma comparação confiável com uma amostra tão pequena. Entretanto, as empresas que usam o modelo do QFD das Quatro Fases parecem ter menos dificuldades de implementação, mas seriam necessárias novas pesquisas com amostras maiores para verificar essa tendência.

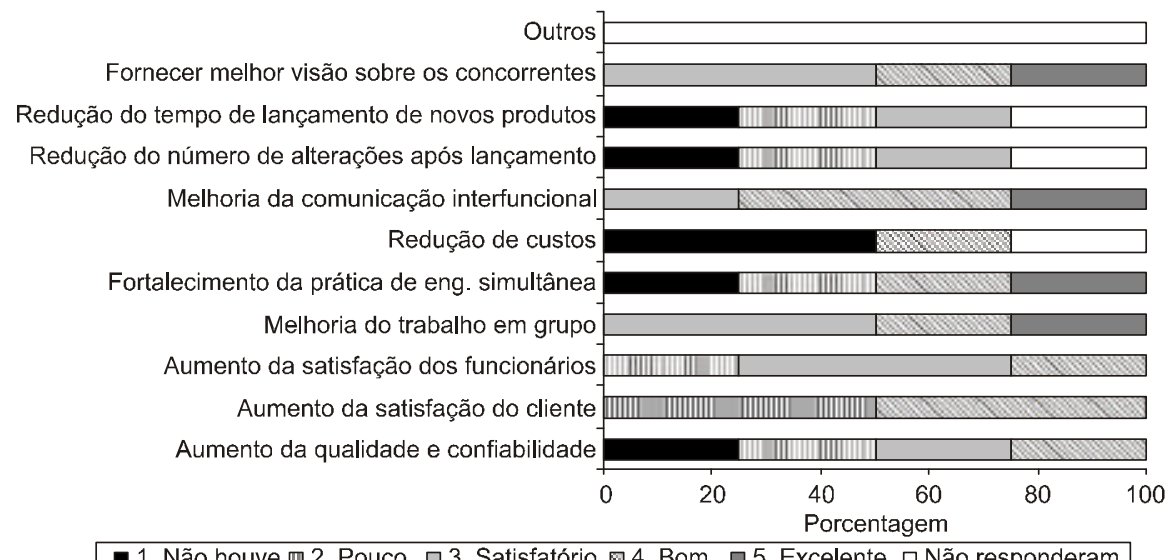

1. Não houve $\square$ 2. Pouco $\square$ 3. Satisfatório $\square$ 4. Bom $\square 5$. Excelente $\square$ Não responderam

Figura 9 - Benefícios do QFD usando uma matriz.

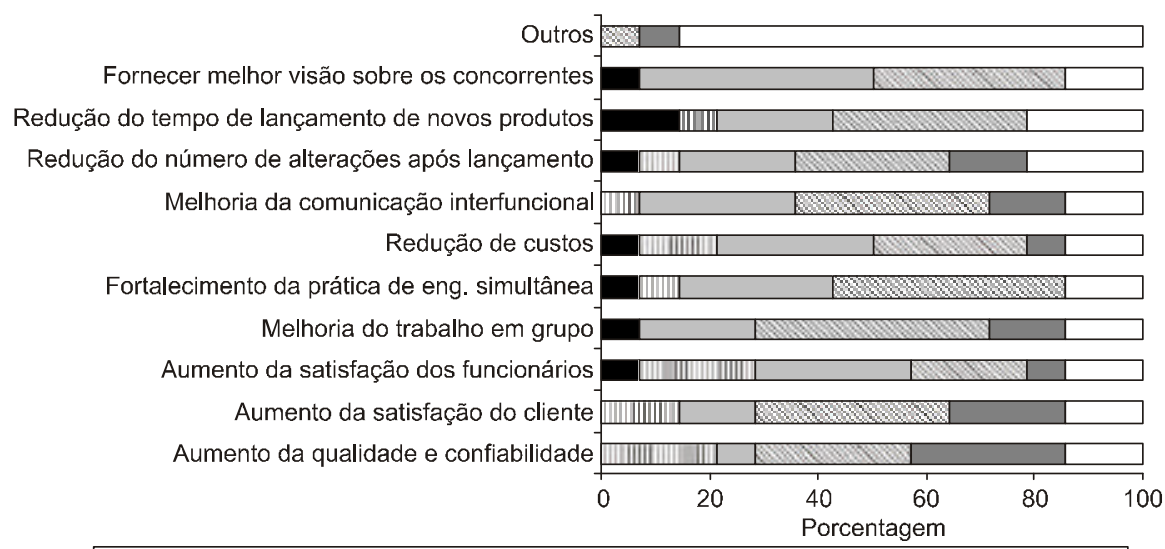

1. Não houve $\square$ 2. Pouco $\square$ 3. Satisfatório $\square$ 4. Bom $\square 5$. Excelente $\square$ Não responderam

Figura 10 - Benefícios do QFD usando mais de uma matriz. 


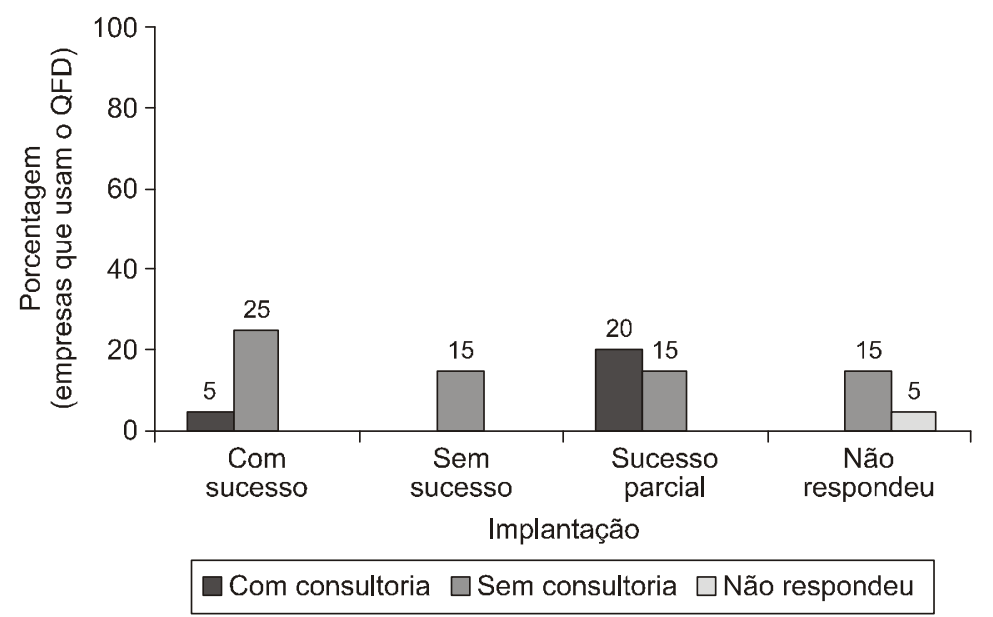

Figura 11 - Influência do número de matrizes na implementação do QFD.

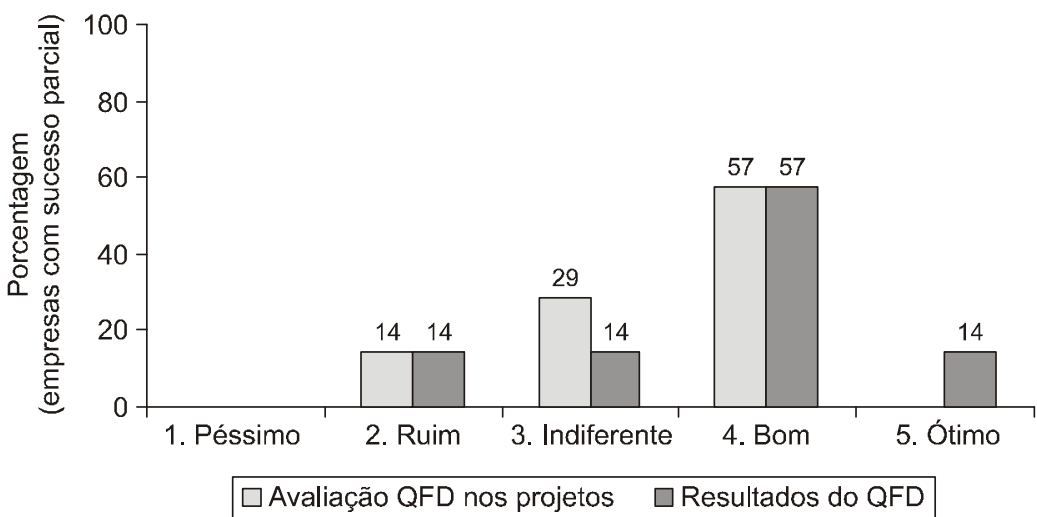

Figura 12 - Sucesso parcial na implementação.

Tabela 2 - Influência do modelo do QFD adotado nas dificuldades de implementação.

\begin{tabular}{|c|c|c|c|c|c|c|}
\hline \multirow{2}{*}{$\begin{array}{ll}\text { Modelo } \\
\text { Dificuldades }\end{array}$} & \multicolumn{2}{|c|}{$\begin{array}{c}\text { Quatro Fases (3 } \\
\text { empresas) }\end{array}$} & \multicolumn{2}{|c|}{$\begin{array}{l}\text { QFD-Estendido (2 } \\
\text { empresas) }\end{array}$} & \multicolumn{2}{|c|}{$\begin{array}{c}\text { Quatro Ênfases (6 } \\
\text { empresas) }\end{array}$} \\
\hline & A & $\mathrm{B}$ & A & $\mathrm{B}$ & A & $\mathrm{B}$ \\
\hline $\begin{array}{l}\text { Dificuldade em função da estrutura organizacional da } \\
\text { empresa }\end{array}$ & $0 \%$ & $0 \%$ & $100 \%$ & $0 \%$ & $50 \%$ & $0 \%$ \\
\hline Falta de suporte gerencial & $33 \%$ & $0 \%$ & $50 \%$ & $50 \%$ & $67 \%$ & $0 \%$ \\
\hline Comprometimento dos membros do grupo & $33 \%$ & $0 \%$ & $0 \%$ & $100 \%$ & $67 \%$ & $0 \%$ \\
\hline Falta de recursos & $33 \%$ & $33 \%$ & $100 \%$ & $0 \%$ & $0 \%$ & $0 \%$ \\
\hline Falta de experiência em QFD & $0 \%$ & $0 \%$ & $100 \%$ & $0 \%$ & $17 \%$ & $33 \%$ \\
\hline $\begin{array}{l}\text { Dificuldade em atribuir peso aos requisitos dos } \\
\text { clientes }\end{array}$ & $0 \%$ & $0 \%$ & $0 \%$ & $0 \%$ & $50 \%$ & $0 \%$ \\
\hline A(s) matriz(es) é(são) muito grande(s) & $33 \%$ & $0 \%$ & $0 \%$ & $0 \%$ & $50 \%$ & $0 \%$ \\
\hline Dificuldade de interpretar os requisitos dos clientes & $33 \%$ & $0 \%$ & $50 \%$ & $0 \%$ & $17 \%$ & $17 \%$ \\
\hline Falta de treinamento & $0 \%$ & $0 \%$ & $50 \%$ & $0 \%$ & $17 \%$ & $0 \%$ \\
\hline Conflitos de opiniões nos grupos & $33 \%$ & $0 \%$ & $0 \%$ & $0 \%$ & $33 \%$ & $0 \%$ \\
\hline
\end{tabular}

$\mathrm{A}=$ concordo; $\mathrm{B}=$ concordo totalmente. 
A Tabela 3 apresenta os principais benefícios da implementação do QFD, separados pelo modelo utilizado pelas empresas. Verifica-se que empresas que utilizaram o QFD das Quatro Fases não encontraram benefícios na categoria "excelente" com o método, o que não ocorreu com as que usaram os outros dois modelos. Entretanto, na maioria dos casos, os benefícios que mais se destacaram não variaram com os diferentes modelos, mas é preciso realizar estudos mais aprofundados, pois a amostra estudada é pequena.

Os principais benefícios encontrados em função das versões adotadas foram: QFD das Quatro Fases: "fornecer melhor visão sobre os concorrentes", "melhoria da comunicação interfuncional", "melhoria do trabalho em grupo" e "aumento da satisfação do cliente"; QFD-Estendido: "melhoria da comunicação interfuncional", "melhoria do trabalho em grupo" e "aumento da satisfação do cliente"; QFD das Quatro Ênfases: "fornecer melhor visão sobre os concorrentes", "melhoria da comunicação interfuncional" e "melhoria do trabalho em grupo". A Figura 13 mostra que as empresas que utilizam o modelo das Quatro Ênfases tendem a conseguir maiores índices de sucesso no uso do QFD. Entretanto, esses resul tados podem ser influenciados pelo tamanho da amostra, precisando ser melhor investigado.
Buscou-se relacionar a influência do tamanho das empresas com o número médio de pessoas nas equipes de QFD, frequiência e duração das reuniões dessas equipes, benefícios do uso do método e avaliação do QFD nos projetos e resultados do QFD, mas não se conseguiu resultados conclusivos em razão da pequena quantidade de empresas estudadas em relação a esses fatores. Também buscou-se relacionar tempo de treinamento com o sucesso na implementação do QFD e a influência de diferentes modelos do QFD nos projetos e em seus resultados, mas também neste caso não se conseguiu extrair resultados com esses cruzamentos.

\section{Síntese dos resultados encontrados e direcionamentos futuros}

Este tópico apresenta uma síntese dos resultados do levantamento realizado, visando a identificar os pontos fortes e fracos no uso do QFD, buscando maior sucesso na aplicação do método. Entende-se que a discussão sobre esses pontos venha a contribuir para maior eficácia e eficiência na utilização do método. Nesse sentido, a discussão é centrada nos pontos pricipais destacados a seguir.

Tabela 3 - Influência do modelo do QFD adotado nos benefícios do QFD.

\begin{tabular}{lccccccccc}
\hline \multicolumn{1}{c}{ Modelo } & \multicolumn{3}{c}{$\begin{array}{c}\text { Quatro Fases (3 } \\
\text { empresas) }\end{array}$} & \multicolumn{2}{c}{$\begin{array}{c}\text { QFD-Estendido (2 } \\
\text { empresas) }\end{array}$} & \multicolumn{3}{c}{$\begin{array}{c}\text { Quatro Enfases (6 } \\
\text { empresas) }\end{array}$} \\
\hline Benefícios & A & B & C & A & B & C & A & B & C \\
Fornecer melhor visão sobre os concorrentes & $33 \%$ & $33 \%$ & $0 \%$ & $50 \%$ & $0 \%$ & $0 \%$ & $33 \%$ & $33 \%$ & $17 \%$ \\
Melhoria da comunicação interfuncional & $33 \%$ & $33 \%$ & $0 \%$ & $0 \%$ & $0 \%$ & $50 \%$ & $17 \%$ & $50 \%$ & $17 \%$ \\
Melhoria do trabalho em grupo & $33 \%$ & $33 \%$ & $0 \%$ & $0 \%$ & $0 \%$ & $50 \%$ & $33 \%$ & $33 \%$ & $17 \%$ \\
Aumento da satisfação dos funcionários & $67 \%$ & $0 \%$ & $0 \%$ & $50 \%$ & $0 \%$ & $0 \%$ & $33 \%$ & $33 \%$ & $0 \%$ \\
Aumento da satisfação do cliente & $33 \%$ & $33 \%$ & $0 \%$ & $0 \%$ & $0 \%$ & $50 \%$ & $17 \%$ & $33 \%$ & $17 \%$ \\
Aumento da qualidade e confiabilidade & $33 \%$ & $33 \%$ & $0 \%$ & $0 \%$ & $50 \%$ & $0 \%$ & $33 \%$ & $17 \%$ & $17 \%$ \\
\hline A = satisfatório; B = bom; C = excelente. & & & & & & & & &
\end{tabular}

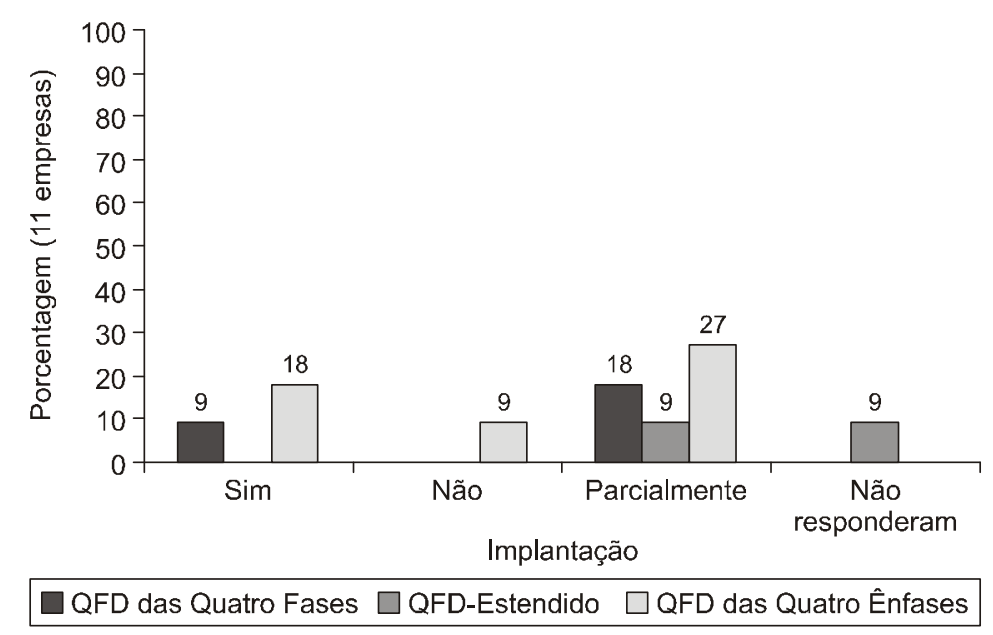

Figura 13 - Influência de diferentes modelos do QFD nos resultados da implementação. 


\subsection{Planejamento sobre a aplicação do QFD}

Um dos aspectos importantes no planejamento para implementação do método é em relação ao treinamento. Esse aspecto é, inclusive, um dos apontados pelas empresas para alcançar sucesso nessa implementação. Nesse sentido, verificou-se que as empresas realizam treinamento do método abaixo do recomendado (Cheng et al., 1995), o que pode influenciar seus resultados; entretanto, isso precisa ser melhor estudado.

Outro aspecto que merece destaque é o modelo teórico adotado, bem como os desdobramentos a serem realizados (custos e confiabilidade, além de tecnologia e qualidade, sendo estes últimos os mais comuns). Na fase de planejamento para a introdução do método, recomenda-se definir quais os desdobramentos almejados. Porém, a realização dos desdobramentos deve ser gradativa, à medida que a empresa vai tendo mais familiaridade com a aplicação do método. Uma referência de tempo, segundo Akao et al. (1987), é que no Japão levam-se dois anos para o QFD ser sistematizado pelas empresas e seis anos para que realmente o método seja incorporado como prática cotidiana. Assim, os desdobramentos mais avançados talvez devam ser realizados após os dois anos de sistematização no uso do QFD.

\subsection{Fatores operacionais relacionados às reuniões e ao trabalho em equipe}

A Tabela 4 resume os principais fatores operacionais na utilização do método, relacionados às reuniões e ao trabalho em equipe.

Apesar da tentativa de verificar as relações desses fatores, descrito no item anterior, não foi possível obter pontos conclusivos sobre eles. Entende-se, portanto, que esses fatores devam ser investigados com maior profundidade nas empresas identificadas, que têm certa experiência no uso do método. De qualquer forma, os aspectos apontados na Tabela 4 podem servir de referência para potenciais usuários do método.

\subsection{Dificuldades no uso do método}

Quanto às dificuldades de utilização do QFD, os resultados encontrados são similares aos de pesquisas realizadas em outros países (Ekdahl \& Gustafsson, 1997; Cristiano et al., 2000; Martins \& Aspinwall, 2001), demonstrando pontos comuns nesse sentido. As dificuldades que mais se des- tacaram na implementação foram: "falta de experiência no uso do método", "falta de comprometimento dos membros das equipes" e "dificuldades em trabalhar com grandes matrizes". Essas dificuldades são, na realidade, pontos que devem ser melhor investigados, buscando melhora metodológica no uso do QFD.

\subsection{Aspectos exemplares na aplicação do QFD}

A grande maioria das empresas tem mais de um projeto concluído, enquanto pouco mais de $30 \%$ já têm mais de três. Para o desenvolvimento desses projetos, verificouse que a maioria das empresas realiza mais de uma matriz, o que é muito importante, pois essas empresas mostraram tendência de conseguir atingir mais benefícios e maior índice de sucesso com o uso do método. Alguns aspectos exemplares foram identificados nas empresas, sejam relativos ao ano de início de implantação (uma empresa citou 1988), treinamento, aspectos relativos às equipes e reuniões, quantidade de projetos já desenvolvidos (uma empresa apontou mais de 20), realização de outros desdobramentos (custos e confiabilidade), assim como avaliação dos resultados no uso do método. Esses aspectos deverão ser analisados com maior detalhamento e publicados oportunamente.

\section{Conclusões e sugestões para trabalhos futuros}

A metodologia adotada (tipo de pesquisa, amostra e técnica de coleta de dados e tabulação dos dados no Excel) se mostrou adequada aos objetivos da pesquisa. Também foi importante a realização de pré-testes para aperfeiçoar o questionário. Na coleta de dados, foram encontradas algumas dificuldades, como conseguir os endereços das empresas da amostra, e problemas de retorno e de extravio de alguns questionários. Na medida do possível, esses problemas foram solucionados pela equipe. Apesar dessas dificuldades, considera-se que os objetivos da pesquisa foram alcançados. Nesse sentido, foi avaliado o grau de introdução do QFD no Brasil, a partir da amostra intencional selecionada, possibilitando identificar benefícios e dificuldades no uso do método, além de outros pontos conclusivos destacados a seguir.

Tabela 4 - Uso do QFD - operação e trabalho em equipe.

\begin{tabular}{lc}
\hline \multicolumn{1}{c}{ Fator operacional } & Resultado principal (maioria das empresas) \\
\hline Áreas funcionais presentes na equipe & Eng. de produto, de processo, produção, qualidade \\
Número de participantes na equipe & 6 membros (em média) \\
Frequiência das reuniões & Semanais \\
Duração das reuniões & De uma a duas horas \\
Número de projetos concluídos & Mais de 1 projeto para mais de 50\% das empresas \\
\hline
\end{tabular}


Com os resultados da pesquisa, verificou-se que o QFD é relativamente pouco usado no Brasil e que sua implementação é relativamente recente, já que a maior parte das empresas iniciou seu uso após 1995. Entre os motivos para a implementação do QFD, destaca-se a busca de melhoria no processo de desenvolvimento de produto, indicando a preocupação das empresas em melhorar esse processo. Assim, o estudo demonstrou que as empresas estão atingindo os principais objetivos que as levaram a aplicar o método.

Neste estudo pôde-se concluir que as empresas devem concentrar esforços para avaliar a implementação do QFD, pois verificou-se que a maioria das empresas não avalia a implementação do QFD, nem seus custos, bem como não registra as melhorias alcançadas. Desse modo, a verificação do custo-benefício na implementação do QFD torna-se limitada. Porém, de forma contraditória, a maioria das empresas considera como "bom" os resultados do QFD e seu efeito nos projetos, mas mais de $35 \%$ consideram que tiveram "sucesso parcial" na implementação, o que precisa ser melhor investigado em futuras pesquisas.

Pode-se concluir que para ter sucesso na implementação do QFD, segundo as empresas, os pontos principais foram: "ter apoio da alta gerência", "analisar e interpretar as informações e resultados adequadamente", "conduzir pesquisa de mercado eficaz" e "proporcionar treinamento adequado". Esses pontos merecem ser melhor explorados.

Um resultado importante desse levantamento foi a identificação de empresas com mais de três projetos concluídos e mais de dois anos de experiência em QFD. Assim, essas empresas podem ser consideradas como referenciais comparativos no uso do método e devem ser objeto de análise para aprofundar este estudo.

\subsection{Futuros desdobramentos da pesquisa}

Os resultados de uma pesquisa desse tipo geralmente apontam algumas perspectivas para trabalhos futuros, tendo em vista que esse tipo de levantamento não permite ir além do que os instrumentos de coleta de dados podem oferecer. Diversos aspectos relacionados à utilização do método podem ser sugeridos, como temas para trabalhos mais aprofundados, visando a prevenir erros e problemas que venham a ter possíveis usuários do QFD. Esses temas potenciais são discutidos a seguir.

Um primeiro tema que merece ser investigado, tão importante quanto estudar mais profundamente as empresas que aplicam o método, é também estudar aquelas que optaram por não aplicá-lo. Entender melhor os fatores que levaram essas empresas à decisão de não usá-lo pode reverter em benefícios em sua utilização, superando alguns dos desafios enfrentados na implementação.

Estudar os aspectos metodológicos do QFD também parece ser uma possibilidade importante. Quaisquer melhorias introduzidas na operação do método podem motivar uma maior aplicação pelas organizações. Algumas das limitações, inclusive citadas pelas empresas estudadas, foram lidar com matrizes muito grandes e despender muito tempo na aplicação do método. Assim, quaisquer investigações que considerem formas de alcançar melhor otimização em sua aplicação pode vir a ampliar seu uso. A investigação do impacto de variáveis como treinamento, consultoria, trabalho em equipe e outras apontadas no decorrer deste trabalho para o sucesso no uso do método também pode contribuir para seu melhor entendimento e utilização.

Outro tema que está sendo considerado como estudo futuro é buscar minimizar as dificuldades e maximizar seus benefícios. Uma das possibilidades que vem sendo estudada é a utilização do projeto axiomático (Suh, 2001). Segundo Suh, o projeto axiomático é uma metodologia de desenvolvimento de projeto que procura gerar princípios que devem guiar o desenvolvimento da melhor solução para um problema proposto. A definição do projeto ideal é aquele que satisfaz o problema proposto da forma mais simples possível, ou seja, o problema é solucionado com o mínimo de informação. A idéia inicial seria desenvolver um procedimento de aplicação do QFD que ao mesmo tempo diminua as dificuldades de implantação e maximize seus benefícios. O projeto axiomático seria usado para desenvolver um roteiro genérico de aplicação do QFD.

Um aspecto adicional que merece ser investigado é sobre a inserção do QFD no processo de desenvolvimento de produto. Como o método surgiu dentro das atividades mais relacionadas ao planejamento da qualidade, deve ser melhor adequado para ser incorporado ao processo de desenvolvimento, principalmente tendo em vista a maior adoção de processos mais recentes, que estruturam o desenvolvimento dos projetos por meio de estágios e gates. Identificar melhor como as atividades inerentes ao QFD devem ser usadas nesses estágios e com que intensidade pode auxiliar as empresas a utilizarem melhor as potencialidades e benefícios que o método oferece. Esse também é um dos trabalhos futuros pretendidos, em que se tem por objetivo, inicialmente, a realização de estudos de casos exploratórios nas empresas identificadas no levantamento apresentado neste trabalho, que têm maturidade no uso do QFD. Assim, visando à continuidade desta pesquisa, duas pesquisas de campo, não excludentes, poderiam ser realizadas. A primeira seria uma série de estudos longitudinais, com o objetivo de investigar a aplicação do QFD em empresas, em um período de três a cinco anos, examinando seu desenvolvimento ao longo do tempo. A segunda possibilidade seria a realização de estudos de casos em maior profundidade, que possibilitassem identificar os fatores de sucesso na aplicação do método, especialmente nas empresas que já alcançaram maior maturidade em sua implementação. 


\section{Agradecimentos}

Os autores agradecem às seguintes instituições e pessoas, sem as quais não seria possível a realização deste trabalho: à FAPESP (bolsa de mestrado, processo: 00/06220-2), ao $\mathrm{CNPq}$ (bolsa de produtividade em pesquisa, processo 301202/ 97-4, e bolsa de iniciação científica do Programa Institucional da UNIMEP-CNPq), ao Fundo de Apoio à Pesquisa (FAP) da UNIMEP, por meio do projeto SEAC 207/99.

Também agradecem ao dr. Rob Hunt, da Macquarie University, Austrália, à sra. Elaine Aspinwall, da Universidade de Birmingham, Inglaterra, por cederem seus questionários de pesquisa e discussão acerca de seus resultados, ao prof. dr. Luiz César R. Carpinetti, da EESC-USP, aos srs. Gyorgy Henyei Júnior e Márcio A. Querichelli pela contribuição na revisão do piloto do questionário, ao prof. dr. Álvaro J. Abackerli por ter cedido dados de pesquisa similar realizada e às empresas que participaram da pesquisa.

Finalmente, os autores agradecem aos revisores da Gestão \& Produção, que contribuíram para o aprimoramento da versão final deste artigo, sugerindo melhorias de forma e conteúdo.

\section{Referências Bibliográficas}

AKAO, Y.; OHFUJI, T.; TOMOYOSHI, N. Surveys and reviews on quality function deployment in Japan. INTERNATIONAL CONFERENCE FOR QUALITY CONTROL. Proceedings... Tokyo: JUSE and IAQ, 1987. p. 171-176.

AKAO, Y. Introdução ao desdobramento da qualidade. Belo Horizonte: Fundação Christiano Ottoni, 1996. 187 p.

CHENG, L. C. et al. QFD: planejamento da qualidade. Belo Horizonte: Fundação Christiano Ottoni, 1995. 261 p.

COSTA, M. M. M. Implantação da metodologia QFD em uma agência bancária. 1999. 87 f. Dissertação (Mestrado em Engenharia Mecânica) - Faculdade de Engenharia Mecânica, Universidade Estadual de Campinas, UNICAMP, Campinas.

CRISTIANO, J. J.; LIKER, J. K.; III WHITE, C. C. Customerdriven product development through quality function deployment in the U.S. and Japan. Journal of Product Innovation Management, v. 17, n. 4, p. 286-308, 2000.

DAMANTE, F. C. Desdobramento da Função Qualidade: um estudo de sua aplicação no Brasil. 1997. 162 f. Dissertação (Mestrado em Administração) - Faculdade de Economia, Administração e Contabilidade, Universidade de São Paulo, USP, São Paulo.

EKDAHL, F.; GUSTAFSSON, A. QFD: the Swedish experience. In: SYMPOSIUM ON QUALITY FUNCTION DEPLOYMENT, 9., 1997. Michigan: Novi, 1997. p. 15-27.

EXAME, Melhores e maiores 2000. São Paulo: Editora Abril, jun. 2000. 364 p. Edição especial.

ISTO É DINHEIRO. 100 maiores lucros ano 2000. Cajamar: Editora Três, out. 2001. 146 p. Edição especial.

MARTINS, A.; ASPINWALL, E. M. Quality function deployment: an empirical study in the UK. Total Quality Management, v. 12, n. 5, p. 575-588, 2001.

MATTAR, F. N. Pesquisa de marketing: edição compacta. São Paulo: Atlas, 1996. 270 p.

MIGUEL, P. A. C.; CARPINETTI, L. R. Some Brazilian experiences on QFD application. In: INTERNATIONAL SYMPOSIUM ON QUALITY FUNCTION DEPLOYMENT, 5., 1999. Belo Horizonte: UFMG, 1999. p. 229-239.
MIGUEL, P. A. C. Qualidade: enfoques e ferramentas. São Paulo: Artliber, 2001. 236 p.

MIGUEL, P. A. C. The state-of-the-art of the Brazilian QFD applications at the top 500 companies. International Journal of Quality and Reliability Management, v. 20, n. 1, p. 7489, 2003.

NOGUEIRA, T. M. et al. Quality assurance: an application of QFD to the production startup of a new engine line. In: INTERNATIONAL SYMPOSIUM ON QUALITY FUNCTION DEPLOYMENT, 5., 1999. Belo Horizonte: UFMG, 1999. p. 26-38.

OHFUJ, T.; ONO, M.; AKAO, Y. Métodos de desdobramento da qualidade (1). Belo Horizonte: Fundação Christiano Ottoni, 1997. 256 p.

OLIVEIRA, A. D. Manual de prática trabalhista, 30. ed. São Paulo: Atlas, 1999. 741 p.

PAIVA, C. L.; CHENG, L. C. O emprego do QFD como ferramenta para a implantação do processo de desenvolvimento de novos produtos em uma pequena empresa de massas alimentícia. In: CONGRESSO BRASILEIRO DE GESTÃO DE DESENVOLVIMENTO DE PRODUTO, 3., 2001. Florianópolis, 2001. 1 CD.

ROSS, H. QFD status at General Motors in the U.S. In: INTERNATIONAL SYMPOSIUM ON QUALITY FUNCTION DEPLOYMENT, 5., 1999. Belo Horizonte: UFMG, 1999.

SASSI, A. C.; MIGUEL, P. A. C. Análise das publicações sobre o QFD no desenvolvimento de serviços e produtos. In: ENCONTRO NACIONAL DE ENGENHARIA DE PRODUÇÃO - ENEGEP, 22., 2002. Curitiba, 2002. CDROM.

SHINA, S. G. Concurrent engineering: new rules for worldclass companies. IEEE Spectrum, v. 28, n. 7, p. 22-26, July 1991.

SUH, N. P. Axiomatic design-advances and applications. New York: Oxford University Press, 2001. 


\title{
QFD APPLICATION IN PRODUCT DEVELOPMENT: SURVEY OF ITS USE AND PERSPECTIVES FOR FUTURE RESEARCH
}

\begin{abstract}
The objective of this work is to evaluate the extension of the use of QFD in Brazil, studying mainly the largest private companies, in order to identify the benefits and difficulties to implement this method as well as companies which already have experience in its use. To achieve this aim, an exploratory survey was carried out, with a nonrandom sample, using as technique a questionnaire sent by surface mail. The return rate was about $21 \%$ and the results showed that a bit more than $18 \%$ use the method. Companies started to make use of QFD during the 90s, showing that the use of QFD in Brazil is still relatively recent. Concerning the difficulties to implement QFD, the major problem was related to the lack of experience with the method. Regarding the benefits, the most important customer satisfaction, and teamwork and functional areas communication improvement. Additionally, the survey identified five companies with experience in QFD, which can be regarded as a reference in terms of the use of the method in the country. Finally, this work points at some perspectives for future research in this subject.
\end{abstract}

Key words: quality function deployment, $Q F D$, product development, quality planning. 